Article

\title{
Desorption of Herbicides from Atmospheric Particulates During High-Volume Air Sampling
}

\author{
Allan J. Cessna ${ }^{1, \dagger} *$, Don T. Waite ${ }^{2, \star}$, Jonathan Bailey ${ }^{3}$, Lorne A. Kerr ${ }^{4, \star}$ and \\ Dwight V. Quiring ${ }^{2, *}$
}

1 Agriculture and Agri-Food Canada, Saskatoon Research Centre, 107 Science Place, Saskatoon, Saskatchewan, S7N 0X2, Canada

2 Environment Canada, 2365 Albert St, Regina, Saskatchewan S4P 4K1, Canada; E-Mails: don.waite@accesscomm.ca; dwightquiring@yahoo.ca

3 National Hydrology Research Centre, 11 Innovation Blvd, Saskatoon, Saskatchewan S7N 3H5 Canada; E-Mail: jon.bailey@ec.gc.ca

4 Research Station, Agriculture and Agri-Food Canada, 5000 Wascana Parkway, Regina, Saskatchewan S4P 3A2, Canada; E-Mail: lnkerr@accesscomm.ca

$\dagger$ Present address: Environment Canada, National Hydrology Research Centre, 11 Innovation Boulevard, Saskatoon, Saskatchewan, S7N 3H5, Canada.

* Retired.

* Author to whom correspondence should be addressed; E-Mail: allan.cessna@ec.gc.ca; Tel.: +1-306-975-5768; Fax: +1-306-975-5143.

Received: 25 July 2011; in revised form: 20 October 2011 / Accepted: 24 October 2011 / Published: 14 November 2011

\begin{abstract}
Pesticides can be present in the atmosphere either as vapours and/or in association with suspended particles. High-volume air sampling, in which air is aspirated first through a glass fibre filter to capture pesticides associated with atmospheric particulates and then polyurethane foam (PUF), often in combination with an adsorbent resin such as XAD-2, to capture pesticides present as vapours, is generally employed during atmospheric monitoring for pesticides. However, the particulate fraction may be underestimated because some pesticides may be stripped or desorbed from captured particulates due to the pressure drop created by the high flow of air through the filter. This possibility was investigated with ten herbicide active ingredients commonly used on the Canadian prairies (dimethylamine salts of 2,4-D, MCPA and dicamba, 2,4-D 2-ethylhexyl
\end{abstract}


ester, bromoxynil octanoate, diclofop methyl ester, fenoxaprop ethyl ester, trifluralin, triallate and ethalfluralin) and seven hydrolysis products (2,4-D, MCPA, dicamba, bromoxynil, diclofop, clopyralid and mecoprop). Finely ground heavy clay soil fortified with active ingredients/hydrolysis products was evenly distributed on the glass fibre filters of high-volume air samplers and air aspirated through the samplers at a flow rate of 12.5 $\mathrm{m}^{3} / \mathrm{h}$ for a 7-day period. The proportion desorbed as vapour from the fortified soil was determined by analysis of the PUF/XAD-2 resin composite cartridges. The extent of desorption from the fortified soil applied to the filters varied from $0 \%$ for each of the dimethylamine salts of 2,4-D, MCPA and dicamba to approximately $50 \%$ for trifluralin, triallate and ethalfluralin.

Keywords: herbicide active ingredient; hydrolysis product; particulate component; vapour component; high-volume air sampling; desorption; preemergence-applied; postemergence-applied

\section{Introduction/Motivation}

Pesticides are known to move from treated agricultural and forested areas into the broader environment. It is generally accepted that the broad diffusion of pesticides into the environment is associated with atmospheric transport and transport in water. Pesticide presence in the atmosphere occurs primarily by three main routes of entry: droplet and vapour drift during application [1-4], post-application vapour losses from the surfaces of treated seed, soil and plants [5-11] and wind erosion of treated soil [12,13].

Input to the atmosphere via application droplet drift is dependent upon nozzle type, sprayer operating parameters (for example, boom height, ground speed) and environmental conditions (for example, wind speed and ambient temperature). Spray droplets $<150 \mu \mathrm{m}$ in diameter in application drift are most prone to movement by atmospheric turbulence because these smaller droplets tend to remain airborne [2,3]. For conventional flat-fan nozzles on ground delivery systems, the amount of drift can be as high as $10 \%$ of the total spray volume whereas, for low-drift nozzles, the value can be as low as $1 \%$ [4]. Complete evaporation of the carrier solvent (generally water) from the droplets results in the formation particulate pesticide residues in the atmosphere.

Post-application vapour losses from soil and plant surfaces are determined by the physical-chemical properties of the pesticide (for example, vapour pressure), the degree of incorporation or penetration into the soil, the extent of binding to soil components, the half-life in soil, the rate of uptake by plants, the pesticide formulation, and environmental conditions (for example, soil temperature and moisture and air temperature and atmospheric turbulence above the soil surface) following application. Significant vapour losses have been reported for surface-applied triallate [S-(2,2,3-trichloro-2propenyl) bis(1-methylethyl)carbamothioate] [14] and trifluralin [2,6-dinitro- $N, N$-dipropyl-4(trifluoromethyl)benzenamine] [6,14] and postemergence-applied 2,4-D [(2,4-dichlorophenoxy)acetic acid] iso-octyl ester [7] and bromoxynil (3,5-dibromo-4-hydroxybenzonitrile) octanoate [9] (Table 1). 
Table 1. Vapour losses of herbicides following pre- and postemergence field application.

\begin{tabular}{lccc}
\hline Herbicide & $\begin{array}{c}\text { Percent Loss } \\
\text { (\%) }\end{array}$ & $\begin{array}{c}\text { Time Period } \\
\text { (d) }\end{array}$ & Reference \\
\hline Preemergence Application & & & \\
Trifluralin surface-applied to moist soil & 90 & $2.5-7$ & {$[6]$} \\
Trifluralin surface-applied & $2-25,18$ & $4.2,24$ & {$[6,14]$} \\
Trifluralin incorporated & $22,23.7$ & 120,67 & {$[5,8]$} \\
Triallate surface-applied & 21 & 24 & {$[14]$} \\
Postemergence Application & & & \\
Diclofop-methyl applied to wheat & $<1$ & 5 & {$[10]$} \\
Bromoxynil butyrate applied to wheat & 16 & 5 & {$[9]$} \\
Bromoxynil octanoate applied to wheat & 7 & 5 & {$[9]$} \\
2,4-D iso-octyl ester applied to wheat & 21 & 7 & {$[7]$} \\
\hline
\end{tabular}

The magnitude of pesticide transport on wind-eroded sediment is related to wind dynamics (for example, speed and turbulence), pesticide half-life in soil as well as the erodibility of soil which is determined by the soil surface roughness, the percentage of wind-erodible aggregates on the soil surface and percentage of the soil surface covered with non-erodible material (for example, crop residues) [15]. Less than $1 \%$ of surface-applied wettable powder formulations of simazine [2-chloro-4,6-bis(ethylamino)-s-triazine] and atrazine [2-chloro-4-(ethylamino)-6-(isopropylamino)-striazine] were lost to the atmosphere due to wind erosion [16]. For three winter erosion events, overall losses of fall-applied trifluralin and triallate incorporated into a clay loam soil were approximately $1.5 \%$ of the amounts applied whereas losses of surface-applied 2,4-D dimethylamine salt (DMA), mecoprop [( \pm )-2-(4-chloro-2-methylphenoxy)propanoic acid] DMA, bromoxynil octanoate and diclofop [( \pm )-2-[4-(2,4-dichlorophenoxy)phenoxy]propanoic acid] methyl ester, also fall-applied, averaged $4.5 \%$ [12].

As a result of these three transport processes, pesticides may be present in the atmosphere as vapours (gases) or associated with the atmospheric aerosol and/or suspended soil particles. As such, pesticides, or their degradation products, may be transported long distances [17] before the removal processes of wet (precipitation) [18] and dry (particulate) [19] deposition deposit them to terrestrial and aquatic ecosystems. Consequently, they may deposit into relatively pristine non-target areas such as wetlands [20], large bodies of water such as the Great Lakes [21] and the Arctic [17].

Ambient air concentrations of pesticides in the atmosphere have been measured using a variety of active and passive samplers. High-volume air sampling is generally accomplished by aspirating air through a solid adsorbent at rates of the order of $25 \mathrm{~L} / \mathrm{min}$ or greater. In most cases, polyurethane foam (PUF), often in combination with an adsorbent resin such as XAD-2, is used to sorb pesticide vapours. The PUF is frequently preceded by a glass fibre filter in order to sample the fraction of the pesticides that is associated with particles suspended in the atmosphere. Such high-volume samplers have been shown to efficiently collect pesticides and, in side-by-side comparisons, to provide reproducible results [22]. However, Bidleman [23] has suggested that, depending on how ambient air temperature and vapour concentrations change during sampling, desorption losses of pesticides from the particles on the filter or adsorption gains to the particles may take place. Under conditions in which desorption losses occur, the pesticide particulate fraction may be underestimated [11,23,24]. This underestimation 
occurs because particulates retained on the filter are exposed to a partial vacuum (due to the pressure drop created by the high volume of air passing through the filter) which may cause some of the pesticide to be stripped or desorbed from particulates captured on the glass fibre filter. The desorbed pesticide would subsequently be retained on the PUF sorbent, thus, simultaneously contributing to an overestimation of the vapour fraction. An accurate assessment of the magnitude of atmospheric concentrations of pesticides (and possible hydrolysis and degradation products), whether as vapour or particulate, is essential for transport and deposition modelling, estimating particle/vapour partitioning, as well as understanding the risks to the public associated with exposure to these contaminants, mainly via inhalation.

The objective of this study was to investigate the phenomenon of pesticide stripping or desorption. This was accomplished by placing finely ground clay soil fortified with ten herbicide active ingredients commonly used in North America and seven hydrolysis products on glass fibre filters in high-volume air samplers fitted with PUF/XAD-2 resin composite cartridges and operating the samplers for a 7-day period. The extent to which active ingredients/hydrolysis products were desorbed from the fortified soil was determined by analysis of the PUF/XAD-2 resin cartridges.

\section{Methods and Models}

\subsection{Fortification of Finely Ground Clay Soil}

Prior to fortification, the Regina heavy clay soil $(10 \mathrm{~g} / \mathrm{kg}$ sand, $290 \mathrm{~g} / \mathrm{kg}$ silt, $710 \mathrm{~g} / \mathrm{kg}$ clay; $31 \mathrm{~g} / \mathrm{kg}$ organic matter), which was collected from a location remote from herbicide application, was analyzed for the active ingredients and hydrolysis products of interest using an extraction solvent system [25] shown to be effective for the extraction of aged herbicide residues from soil. No active ingredients or hydrolysis products were detected in the soil and this batch of soil was used for all desorption experiments.

The heavy clay soil, which had been finely ground using a mortar and pestle, was fortified as follows: a methanol solution $(2 \mathrm{~mL} ; 50 \mu \mathrm{g} / \mathrm{mL}$ of each active ingredient and hydrolysis product) was added to a glass vial containing $10 \mathrm{~g}$ of the ground clay soil resulting in a fortification level of $10 \mu \mathrm{g} / \mathrm{g}$ for each chemical. Methanol $(3 \mathrm{~mL})$ was then added to the vial and the mixture stirred to create a homogeneous slurry, and the vial placed in a fume hood overnight to permit evaporation of the methanol. The dry fortified soil was then mixed to a fine consistency using a stainless steel spatula and the vial capped and wrapped with aluminium foil. The fortified soil was then maintained at room temperature in the dark for three weeks to "age" the herbicide residues.

\subsection{Desorption Experiments}

The desorption experiments were carried out in the fall (September/October) when it was expected that herbicide concentrations in ambient air would be low, relative to earlier in the growing season. High-volume air samplers (Model PS-1, General Metals Works, Village of Cleves, OH, USA), designed to collect airborne organic chemicals, were used in this study. Each sampler was equipped with a PUF/XAD-2 resin composite cartridge preceded by a glass fibre filter [11]. The air flow through the samplers $\left(12.5 \mathrm{~m}^{3} / \mathrm{h}\right)$ was calibrated in the field using a Sierra-Misco Inc. (Berkeley, CA, USA) 
orifice head and was monitored daily by integral Venturi/Magnehelic assemblies. In each experiment, the samplers were operated continuously for a 7-day period resulting in a total air flow of $\sim 2100$ $\mathrm{m}^{3} /$ week. Weekly sampling had been used in a previous study [26] because it permitted seasonal sampling (spring, summer, fall) without overtaxing the capacity of the analytical laboratory. The intake of each sampler was $1 \mathrm{~m}$ above ground level. The sampling unit in the high-volume PS-1 samplers consisted of a 102-mm dia. borosilicate microfibre filter (Micro Filtration Systems, Dublin, CA, USA) in front of a PUF/XAD-2 resin composite cartridge. The cartridge contained $25 \mathrm{~mL}$ of XAD-2 adsorbent resin (Caledon Laboratories Ltd., Georgetown, ON, USA) between 25-mm and 50-mm PUF plugs housed in a $60-\mathrm{mm}$ i.d. by $125-\mathrm{mm}$ long glass cylinder with a stainless steel wire mesh support screen. The filter and the composite cartridge collected particulate and vapour components of the air, respectively. Prior to assembly of the sampling cartridges for field use, the PUF plugs and the XAD-2 adsorbent resin were solvent (acetone) cleaned and monitored for background interferences.

\subsection{Herbicide Active Ingredients}

\subsubsection{September Experiments}

Seven herbicide active ingredients found in commercially available formulated products were investigated in four desorption experiments. Five active ingredients were postemergence-applied (2,4-D DMA, dicamba (3,6-dichloro-2-methoxybenzoic acid) DMA, MCPA [(4-chloro-2-methylphenoxy)acetic acid] DMA, bromoxynil octanoate, diclofop methyl ester) and two were preemergence-applied (trifluralin and triallate) (Mixture A). In each experiment, three high-volume air samplers were simultaneously operated on a grassed area situated on the Agriculture and Agri-Food Canada Research Station near Regina, Saskatchewan. In one sampler, finely ground clay soil $(0.5 \mathrm{~g})$, fortified with the seven active ingredients at $10 \mu \mathrm{g} / \mathrm{g}$, was evenly distributed over the surface of the glass fibre filter and then covered with a second glass fibre filter such that the fortified soil was contained between the two filters. The other two samplers were used as controls and were operated with a single glass fibre filter to enable correction for possible herbicide concentrations in the air at the study site. At the end of each 7-day sampling period, the fortified soil together with the two glass fibre filters were removed as a unit, the outer edges $(\sim 1 \mathrm{~cm})$ of the filters folded inward together to retain the fortified soil between the filters, and the folded unit wrapped in solvent-washed aluminum foil. The PUF/XAD-2 resin composite cartridges were also wrapped in aluminum foil prior to transport to the laboratory for extraction and analysis.

\subsubsection{October Experiments}

Because initial analyses showed no desorption of the dimethylamine salts of 2,4-D, MCPA and dicamba, these active ingredients were not studied further, and other active ingredients were included for study. Four postemergence-applied active ingredients (bromoxynil octanoate, diclofop methyl ester, 2,4-D 2-ethylhexyl ester, fenoxaprop \{( \pm )-2-[4-[6-chloro-1,3-benzoxazol-2-yloxy)phenoxy] propionic acid \} ethyl ester) and three preemergence-applied active ingredients (trifluralin, triallate and ethalfluralin [( $N$-ethyl- $N$-(2-methyl-2-propenyl)-2,6-dinitro-4-(trifluoromethyl)benzenamine]) (Mixture B) were investigated. In these 7-day experiments, five high-volume air samplers were simultaneously 
operated at the Research Station site. Finely ground clay soil fortified with the seven active ingredients was added to three of the samplers while the other two samplers were used as controls.

\subsection{Hydrolysis Products}

\subsubsection{October Experiments}

In these experiments, the hydrolysis products of postemergence-applied active ingredients included 2,4-D, MCPA, dicamba, bromoxynil, diclofop, mecoprop and clopyralid (3,6-dichloro-2pyridinecarboxylic acid). In addition, the three preemergence-applied herbicides (trifluralin, triallate and ethalfluralin) were included (Mixture C). Finely ground clay soil fortified with the seven hydrolysis products plus the three preemergence-applied herbicides were added to three samplers while the two samplers were used as controls.

\subsection{Sample Extraction and Extract Analysis}

\subsubsection{PUF/XAD-2 Resin Composite Cartridge}

Each assembled PUF/XAD-2 resin cartridge was Soxhlet extracted with acetone $(700 \mathrm{~mL})$ for $16 \mathrm{~h}$. The acetone extract was concentrated to $<10 \mathrm{~mL}$ using a rotary evaporator and transferred to a $50-\mathrm{mL}$ graduated centrifuge tube along with three $1.5-\mathrm{mL}$ acetone rinses of the rotary evaporator flask.

\subsubsection{Mixtures A and C}

The acetone extract was concentrated to $<1 \mathrm{~mL}$ with a stream of dry nitrogen gas and then methylated with ethereal diazomethane according to the procedure of Grover et al. [27]. iso-octane $(200 \mu \mathrm{L})$ was added to the methylated extract along with $10 \mu \mathrm{g}$ of dacthal in acetone $(100 \mu \mathrm{L})$ as an internal standard and the extract similarly concentrated to $<1 \mathrm{~mL}$. Hexane $(4 \mathrm{~mL})$ was added to the centrifuge tube and the extract similarly concentrated to $<1 \mathrm{~mL}$ and then taken to $1-\mathrm{mL}$ final volume with hexane prior to gas chromatographic analysis.

\subsubsection{Mixture B}

The Soxhlet acetone extract was concentrated to a 1-mL volume as described for Mixtures A and C but without methylation with ethereal diazomethane.

\subsubsection{Glass Fibre Filter/Soil Unit}

\subsubsection{Mixtures A and C}

The glass fibre filter/soil unit was removed from the aluminum foil wrapping and the edges of the filter/soil unit folded inward until in a cylindrical configuration. The folded filters were then placed in a 40-mL teflon-coated polypropylene centrifuge tube containing $25 \mathrm{~mL}$ of extraction solvent [acetonitrile + water + acetic acid $(70+30+2.5 \mathrm{v} / \mathrm{v} / \mathrm{v})]$ which was shown by Smith [28] to be effective for extracting herbicides from weathered soils. After sealing with a teflon-lined cap, the 
centrifuge tube was placed on a wrist-action shaker at moderate speed for $16 \mathrm{~h}$. The mixture in the tube was then centrifuged at $3000 \mathrm{rpm}$ for 4 min and the supernatant decanted into a $500-\mathrm{mL}$ separatory funnel. An additional $5 \mathrm{~mL}$ of extraction solvent was added to the centrifuge tube, the tube shaken by hand for $1 \mathrm{~min}$, and the mixture similarly centrifuged and decanted into the separatory funnel.

The preemegence-applied active ingredients were extracted into hexane $(100 \mathrm{~mL}, 50 \mathrm{~mL})$ after adjusting the $\mathrm{pH}$ of the extract to $\sim 12$ with aqueous sodium hydroxide $(0.1 \mathrm{M} ; 250 \mathrm{~mL})$. The combined hexane extracts were dried over anhydrous sodium sulfate $(1 \mathrm{~g})$, decanted into a $250-\mathrm{mL}$ evaporating flask along with a $2-\mathrm{mL}$ hexane rinse of the sodium sulfate and, following the addition of iso-octane $(200 \mu \mathrm{L})$ and dacthal $(10 \mu \mathrm{g})$, were concentrated to a $1-\mathrm{mL}$ volume as described above prior to gas chromatographic analysis. The three postemergence-applied dimethylamine salt active ingredients and seven hydrolysis products were then extracted with diethyl ether $(100 \mathrm{~mL}, 50 \mathrm{~mL})$ after the $\mathrm{pH}$ of the extract was adjusted to $\sim 2$ by the addition of concentrated sulfuric acid $(1 \mathrm{~mL})$. The combined ether extracts were similarly dried and concentrated to approximately $1 \mathrm{~mL}$. The ether extract was then methylated with ethereal diazomethane and concentrated to $1 \mathrm{~mL}$ (as described for the PUF/XAD-2 resin composite cartridge for Mixtures A and C) prior to gas chromatographic analysis.

\subsubsection{Mixture B}

The glass fibre filter/soil unit fortified with Mixture B was similarly folded and then Soxhlet extracted with $300 \mathrm{~mL}$ of acetone for $6 \mathrm{~h}$. The acetone extract was concentrated to a 1-mL volume (as described for the PUF/XAD-2 resin composite cartridge for Mixture B) prior to gas chromatographic analysis.

\subsubsection{Gas Chromatographic Analysis}

Quantification and confirmation of the herbicide active ingredients and the methyl derivatives of the hydrolysis products in the extracts were carried out using a Hewlett-Packard model 5890A gas chromatograph interfaced to the model 5970B mass selective detector (MSD) which was operated in the selected ion monitoring mode. The GC-MSD system was controlled with the model 5895A data station and the GC was equipped with a $25-\mathrm{m}$ by $0.2-\mathrm{mm}$ i.d. Ultra-1 capillary column (Hewlett-Packard; film thickness of $0.11 \mu \mathrm{m})$. Injections $(2 \mu \mathrm{L})$ of sample extracts were performed using the model $7673 \mathrm{~A}$ autoinjector. The split-splitless injector was operated in the splitless mode and maintained at a temperature of $230^{\circ} \mathrm{C}$. The helium carrier gas flow was $25 \mathrm{~cm} / \mathrm{s}$, and the column temperature program consisted of an initial temperature of $70{ }^{\circ} \mathrm{C}$ for $1 \mathrm{~min}$ followed by a temperature increase of $5{ }^{\circ} \mathrm{C} / \mathrm{min}$ to $270{ }^{\circ} \mathrm{C}$ and hold for $1 \mathrm{~min}$. The capillary interface between the GC and the MSD was maintained at $280{ }^{\circ} \mathrm{C}$ throughout each run. The retention times for the active ingredients and the methylated hydrolysis products under these operating conditions are presented in Table 2. Three or four ions, characteristic of each analyte, were monitored for confirmation purposes (Table 2). 
Table 2. The methylated hydrolysis products and the preemergence-applied and postemergence-applied active ingredients in order of increasing retention time, the ions monitored, and the relative response of ions used for confirmation purposes.

\begin{tabular}{|c|c|c|c|c|}
\hline $\begin{array}{l}\text { Hydrolysis Product/ } \\
\text { Active Ingredient }\end{array}$ & $\begin{array}{l}\text { Retention Time } \\
\text { (min) }\end{array}$ & $\begin{array}{c}\text { Ions } \\
\text { Monitored }\end{array}$ & $\begin{array}{l}\text { Ions Used for } \\
\text { Confirmation * }\end{array}$ & Ion Ratio $^{\dagger}$ \\
\hline \multicolumn{5}{|c|}{ Methylated Hydrolysis Products } \\
\hline Clopyralid methyl ester & 18.31 & $110,147,174$ & $174 / 147$ & $0.32 \pm 0.02$ \\
\hline Dicamba methyl ester & 20.49 & $187,203,205,234$ & $205 / 203$ & $0.65 \pm 0.02$ \\
\hline Mecoprop methyl ester & 21.37 & $142,169,228$ & $142 / 169$ & $0.96 \pm 0.07$ \\
\hline MCPA methyl ester & 21.62 & $125,141,155,214$ & $155 / 141$ & $0.70 \pm 0.03$ \\
\hline Bromoxynil methyl ether & 22.88 & $248,276,291$ & $276 / 291$ & $0.52 \pm 0.03$ \\
\hline 2,4-D methyl ester & 23.18 & $175,199,234,236$ & $234 / 199$ & $0.60 \pm 0.02$ \\
\hline \multicolumn{5}{|c|}{ Preemergence-Applied Active Ingredients } \\
\hline Ethalfluralin & 24.40 & $276,292,316$ & $316 / 276$ & $0.79 \pm 0.11$ \\
\hline Trifluralin & 24.83 & $264,306,335$ & $264 / 306$ & $0.83 \pm 0.09$ \\
\hline Triallate & 27.90 & $86,128,143,268$ & $268 / 86$ & $0.48 \pm 0.07$ \\
\hline \multicolumn{5}{|c|}{ Postemergence-Applied Active Ingredients } \\
\hline 2,4-D 2-ethylhexyl ester & 34.71 & $220,222,332$ & $222 / 220$ & $0.67 \pm 0.05$ \\
\hline Bromoxynil octanoate & 37.26 & $260,323,403$ & $260 / 323$ & $0.78 \pm 0.04$ \\
\hline Diclofop methyl ester & 38.35 & $253,281,340$ & $253 / 340$ & $1.09 \pm 0.12$ \\
\hline Fenoxaprop ethyl ester & 41.36 & $261,288,347$ & $347 / 288$ & $1.03 \pm 0.04$ \\
\hline
\end{tabular}

The presence of a herbicide was considered to be confirmed if: (i) all ions monitored were present; (ii) a peak appeared at the retention time $( \pm 0.02 \mathrm{~min})$ obtained for a standard solution of the herbicide in the reconstructed chromatograms of all ions monitored; and (iii) the peak area ratio was within $\pm 30 \%$ of the ratio obtained using a standard solution of the herbicide.

\subsubsection{Recovery Experiments}

Active ingredient and hydrolysis product recoveries from the finely ground Regina heavy clay soil were determined by spreading $0.5 \mathrm{~g}$ of the respective soil fortified as described for the field desorption experiments onto a 102-mm diameter glass fibre filter, covering the soil with a second filter, and folding and extracting the filter/soil unit as described for the field samples. The PUF/XAD-2 resin composite cartridges were fortified with active ingredients and hydrolysis products by spotting $50 \mu \mathrm{L}$ of an acetone solution containing $5 \mu \mathrm{g}$ of each compound onto the upstream surface of the upstream PUF plug in a PUF/XAD-2 resin cartridge. The cartridge was then placed in a fume hood during evaporation of the acetone and extracted as described for the field samples. The dimethylamine salts of 2,4-D, MCPA and dicamba were not included in the recovery experiments because it would not have been possible to distinguish the recoveries of the dimethylamine salts from those of the corresponding hydrolysis product since methylation of either compound both would have resulted in the same methyl ester used for quantification. Recoveries of the hydrolysis products 2,4-D, MCPA and dicamba were considered to be representative of recoveries of the corresponding dimethylamine salts. Percent 
recoveries were calculated by dividing the mass $(\mu \mathrm{g})$ of each active ingredient/hydrolysis product in the resulting extract from either the filter/soil unit or the PUF/XAD-2 resin cartridge by the fortification amount $(5 \mu \mathrm{g})$ and multiplying by 100 .

\section{Results and Discussion}

\subsection{Active Ingredients and Hydrolysis Products}

The herbicides selected for study are extensively used for weed control in crop production on the Canadian prairies. The three preemergence-applied active ingredients (trifluralin, triallate and ethalfluralin), which are applied to the soil surface prior to emergence of the crop, are generally incorporated into the soil to minimize vapour loss due to their relatively high vapour pressures (Table 3). Their dissipation from soil is characterized, in part, by a rapid initial vapour loss followed by further vapour loss over the growing season when soil surface moisture conditions are adequate [8].

With postemergence-applied active ingredients, the proportion of the application not intercepted by the crop/weed canopy and depositing on the soil surface is dependent upon the coverage provided by the crop/weed canopy. In the present study, three amine salts (2,4-D DMA, MCPA DMA and dicamba DMA) and four esters (2,4-D 2-ethylhexyl, diclofop methyl, fenoxaprop ethyl and bromoxynil octanaote) of three carboxylic acids and one phenol (bromoxynil) were investigated. After field application, esters and salts of acid herbicides are subject to relatively rapid hydrolysis to the free acid on soil and plant surfaces and in aquatic ecosystems. For example, the half-lives of 2,4-D iso-octyl ester [7], diclofop methyl ester [28] and bromoynil octanoate [9] on the soil surface were $\sim 3$ days, $<1$ days, and $\sim 4$ days, respectively (Table 3 ). The corresponding half-lives on plant (wheat, Triticum aestivum L.) surfaces were also short ( $\sim 3$ days [7], $<2$ days [10] and $<2$ days [9]). Rapid ester hydrolysis is also expected following application droplet drift into aquatic environments. In natural waters, half-lives of $\sim 2$ days have been reported for 2,4-D iso-octyl and butoxyethyl esters [29] and bromoxynil octanoate [30]. The dissociation of the salts of the acid herbicides to the corresponding free carboxylate anion is generally considered to be rapid. Consequently, with the exception of fenoxaprop ethyl ester, the free acids or hydrolysis products of six active ingredients including two additional hydrolysis products (mecoprop and clopyralid) were also investigated. In total, the active ingredients/hydrolysis products studied represented a wide range in vapour pressures, soil sorption coefficients and field half-lives (Table 3). 
Table 3. Characteristics * of each active ingredient/hydrolysis product and, in the order of decreasing vapour pressure, the percent of each analyte captured on the PUF/XAD-2 composite resin cartridge during the desorption experiments.

\begin{tabular}{|c|c|c|c|c|c|c|c|c|}
\hline $\begin{array}{l}\text { Active Ingredient/ } \\
\text { Hydrolysis Product }\end{array}$ & $\begin{array}{c}\text { Vapour } \\
\text { Pressure } \\
\left(\text { Pa at } 25^{\circ} \mathrm{C}\right)\end{array}$ & $\begin{array}{c}\text { Average Soil Sorption } \\
\text { Coefficient }\left(\mathrm{K}_{\mathrm{oc}}\right) \\
(\mathrm{mL} / \mathrm{g})\end{array}$ & $\begin{array}{l}\text { Average Field } \\
\text { Half-Life } \\
\text { (d) }\end{array}$ & $\begin{array}{c}\mathrm{p} K_{\mathrm{a}} \\
\text { Value }\end{array}$ & $\begin{array}{c}\text { Number of } \\
\text { Desorption } \\
\text { Experiments }\end{array}$ & $\begin{array}{l}\text { Number of } \\
\text { Detections }\end{array}$ & $\begin{array}{c}\text { Number of } \\
\text { Background } \\
\text { Samples }\end{array}$ & $\begin{array}{c}\text { Percent } \\
\text { Desorbed } \\
\text { Mean } \pm \text { SD }\end{array}$ \\
\hline Trifluralin & $14.7 \times 10^{-2}$ & 7000 & 45 & - & 10 & 10 & 12 & $49 \pm 18$ \\
\hline Triallate & $14.7 \times 10^{-2}$ & 2400 & 82 & - & 10 & 10 & 12 & $48 \pm 21$ \\
\hline Ethalfluralin & $10.9 \times 10^{-2}$ & 4000 & 60 & - & 6 & 6 & 4 & $55 \pm 28$ \\
\hline Dicamba & $4.5 \times 10^{-3}$ & 2 & $<14$ & 1.97 & 3 & 0 & 2 & 0 \\
\hline Clopyralid & $1.36 \times 10^{-3}$ & 6 & 40 & 2.0 & 3 & 0 & 2 & 0 \\
\hline Bromoxynil octanoate & $6.4 \times 10^{-4}$ & 10000 & $\sim 4[9]$ & - & 7 & 7 & 10 & $5.5 \pm 6.5$ \\
\hline Mecoprop & $3.1 \times 10^{-4}$ & 20 & 21 & 3.68 & 3 & 0 & 2 & 0 \\
\hline MCPA & $2.0 \times 10^{-4}$ & 110 & $5-6$ & 3.73 & 3 & 0 & 2 & 0 \\
\hline $\begin{array}{l}\text { 2,4-D 2-ethylhexyl } \\
\text { ester }\end{array}$ & $4.79 \times 10^{-5}[31]$ & 100 (estimated) & $\sim 3[7]$ & - & 3 & 3 & 2 & $3.7 \pm 2.8$ \\
\hline Diclopfop methyl ester & $2.13 \times 10^{-5}$ & 16000 & $<1[28]$ & - & 7 & 6 & 10 & $2.0 \pm 1.3$ \\
\hline $2,4-\mathrm{D}$ & $1.9 \times 10^{-5}$ & 20 & 10 & 2.73 & 3 & 0 & 2 & 0 \\
\hline Bromoxynil & $6.2 \times 10^{-6}$ & $-\S$ & 7 & 3.86 & 3 & 2 & 2 & $0.1 \pm 0.1$ \\
\hline Fenoxaprop ethyl ester & $4.3 \times 10^{-6}$ & 9490 & 9 & - & 3 & 2 & 2 & $0.2 \pm 0.2$ \\
\hline Diclofop & $9.7 \times 10^{-9}[31]$ & $-\S$ & 30 & 3.43 & 3 & 0 & 2 & 0 \\
\hline 2,4-D DMA salt ${ }^{\#}$ & $0[32]$ & - & - & - & 3 & 0 & 8 & 0 \\
\hline Dicamba DMA salt & $0[32]$ & - & - & - & 3 & 0 & 8 & 0 \\
\hline MCPA DMA salt ${ }^{\#}$ & $0[32]$ & - & - & - & 3 & 0 & 8 & 0 \\
\hline
\end{tabular}

* All values are from the Herbicide Handbook [33], unless otherwise indicated; ${ }^{\dagger}$ Number of desorption experiments in which the active ingredient/hydrolysis product was detected in the extract of the PUF/XAD-2 resin composite cartridge; ${ }^{\S}$ No data; ${ }^{\#}$ The soil sorption coefficients, field half-lives and $\mathrm{p} K_{\mathrm{a}}$ values of the dimethylamine salts of 2,4-D, MCPA and dicamba are considered to be the same as those of the corresponding acids . 


\subsection{Active Ingredient/Hydrolysis Product Recoveries}

Recoveries of the active ingredients/hydrolysis products from the fortified PUF/XAD-2 resin composite cartridges were generally higher than those from the glass fibre filter/soil units (Table 4). For example, mean recoveries of the hydrolysis products from the PUF/XAD-2 resin cartridges ranged from 72 to $99 \%$ whereas those from the filter/soil unit ranged from 40 to $91 \%$. This trend was also evident for the preemergence- and postemergence-applied active ingredients. With respect to the hydrolysis products, the lowest recoveries were obtained for dicamba and clopyralid, most likely due to lower extraction efficiency because of their lower $\mathrm{p} K_{\mathrm{a}}$ values (Table 3). Standard deviation values were generally $15 \%$ or less.

Table 4. Percent recoveries of active ingredients/hydrolysis products from fortified PUF/XAD-2 resin composite cartridges and from glass fibre filter/soil units.

\begin{tabular}{lcclcc}
\hline Active Ingredient & $\begin{array}{c}\text { PUF/XAD-2 } \\
\text { Resin Cartridge } \\
(\boldsymbol{n = 2 )}\end{array}$ & $\begin{array}{c}\text { Filter/Soil } \\
\text { Unit } \\
(\boldsymbol{n}=\mathbf{6})\end{array}$ & $\begin{array}{c}\text { Hydrolysis } \\
\text { Product }\end{array}$ & $\begin{array}{c}\text { PUF/XAD-2 } \\
\text { Resin Cartridge } \\
(\boldsymbol{n}=\mathbf{2})\end{array}$ & $\begin{array}{c}\text { Filter/Soil } \\
\text { Unit } \\
(\boldsymbol{n}=\mathbf{6})\end{array}$ \\
\hline Postemergence-Applied Active Ingredients & & \multicolumn{2}{c}{ Hydrolysis Product } \\
Bromoxynil octanoate & $112 \pm 36$ & $122 \pm 8$ & Bromoxynil & $95 \pm 7$ & $81 \pm 3$ \\
Diclofop methyl ester & $127 \pm 6$ & $86 \pm 11$ & Diclofop & $91 \pm 7$ & $91 \pm 12$ \\
2,4-D 2-ethyl-hexyl ester & $142 \pm 7$ & $81 \pm 6$ & $2,4-\mathrm{D}$ & $99 \pm 11$ & $83 \pm 4$ \\
Fenoxaprop ethyl ester & $138 \pm 5$ & $35 \pm 3$ & MCPA & $88 \pm 13$ & $71 \pm 7$ \\
& & & Dicamba & $80 \pm 15$ & $59 \pm 4$ \\
& & & Clopyralid & $72 \pm 24$ & $40 \pm 4$ \\
& & & Mecoprop & $87 \pm 14$ & $67 \pm 4$ \\
Preemergence-Applied Active Ingredients $*$ & & & & \\
Trifluralin & $110 \pm 13$ & $70 \pm 12$ & Trifluralin & $91 \pm 7$ & $99 \pm 4$ \\
Triallate & $149 \pm 10$ & $84 \pm 10$ & Triallate & $91 \pm 7$ & $75 \pm 4$ \\
Ethalfluralin & $113 \pm 15$ & $68 \pm 12$ & Ethalfluralin & $84 \pm 2$ & $93 \pm 4$ \\
\hline
\end{tabular}

* Recoveries of trifluralin, triallate and ethalfluralin were determined under the extraction procedures for both the ester active ingredients and the extraction procedures for the hydrolysis products (free acids).

\subsection{Desorption Experiments}

Although ten desorption experiments were carried out, the number of times that desorption of each herbicide/hydrolysis product was measured varied from ten to three (Table 3). Both the PUF/XAD-2 resin composite cartridges and the glass fibre filter/soil units were analyzed with the intent of trying to achieve a mass balance; that is, of the approximately $5 \mu \mathrm{g}$ of each active ingredient/hydrolysis product applied with the fortified soil to the filters, to account for what proportion of that was desorbed and captured on the PUF/XAD-2 resin cartridge and what proportion was retained on the filter/soil unit. However, achieving a mass balance was not realistic because recoveries of the active ingredients/hydrolysis products from the PUF/XAD-2 resin cartridges and the filter/soil units at this fortification level were not quantitative and differed significantly (Table 4). Therefore, the amount of each active ingredient/hydrolysis product captured on the PUF/XAD-2 resin cartridges (corrected for the amount captured from ambient air concentrations) was considered to be the amount desorbed from 
the filter/soil unit and was expressed as a proportion of the corresponding amounts added with the fortified soil to the filter/soil unit. For most of the active ingredients/hydrolysis products, the standard deviation values associated with the recoveries from the fortified XAD-2 resin cartridges and the filter/soil units generally exceeded the corresponding proportions desorbed (Table 3).

\subsection{Active Ingredients/Hydrolysis Products Desorbed}

Each of the desorption experiments was designed such that two high-volume air samplers were used as controls to determine herbicide active ingredients or hydrolysis products present in the air at the time the desorption experiments were carried out. Ambient air concentrations of the dimethylamine salts of 2,4-D, dicamba and MCPA were not detected during the desorption control experiments nor were the hydrolysis products 2,4-D, MCPA, mecoprop, dicamba, bromoxynil, diclofop and clopyralid. However, background concentrations of the preemergence-applied and postemergence-applied active ingredients were detected, most likely because of fall application. Generally, the amounts of each active ingredient captured on the PUF/XAD-2 resin composite cartridges of the control samplers were of similar magnitude. The lowest background amounts (a few nanograms) were detected for diclofop methyl ester (detected in 2 of 10 background samples) and fenoxaprop ethyl ester (detected in 1 of 2 background samples). Higher amounts $(<100 \mathrm{ng})$ were detected for trifluralin, ethalfluralin, 2,4-D 2-ethylhexyl ester and bromoxynil octanoate. The maximum amounts $(<1000 \mathrm{ng})$ were detected for triallate. The average of the amounts detected on the PUF/XAD-2 resin composite cartridge in the control samplers was subtracted from the corresponding amounts detected in samplers with the fortified soil.

There was no detectable desorption of the dimethyamine salts of 2,4-D, dicamba and MCPA from the fortified heavy clay soil contained in the glass fibre filter/soil unit during high-volume air sampling over a 7-day period. This was not surprising because the polar dimethylamine salts, which have negligible vapour pressures under field conditions (Table 3), would be strongly sorbed to the clay soil and, as salts, no partitioning to the gas phase during sampling would have occurred [34].

Bromoxynil was the only hydrolysis product desorbed in measurable amounts $(\sim 0.1 \%)$ even though its vapour pressure is very low (Table 3). Desorption most likely occurred because it is less polar than the other hydrolysis products. Bromoxynil is a phenol and, compared to the other five hydrolysis products which are carboxylic acids, is a relatively weak acid (see $\mathrm{p} K_{\mathrm{a}}$ values, Table 3 ) and therefore less polar. Even dicamba and clopyralid, whose vapour pressures are approximately three orders of magnitude greater than that of bromoxynil, were not desorbed. Thus, the polarity of 2,4-D, MCPA, mecoprop, dicamba, diclofop and clopyralid appears to have played a greater role in their desorption than their relative vapour pressures.

The three preemergence-applied active ingredients consisted of one thiocarbamate (triallate) and two dinitroaniline (trifluralin and ethalfluralin) compounds. The four postemergence-applied active ingredients (bromoxynil octanoate, diclofop methyl ester, 2,4-D 2-ethylhexyl ester and fenoxaprop ethyl ester) are all esters. All of these active ingredients are relatively non-polar and it is apparent from the data in Table 3 that the proportion of each active ingredient desorbed was dependent on its vapour pressure. Of these seven active ingredients, the three preeemergence-applied active ingredients have the highest vapour pressures and are desorbed in greatest proportion. Approximately $50 \%$ of trifluralin 
triallate and ethalfluralin were desorbed from the heavy clay soil under the conditions of high-volume air sampling. The highest vapour pressures among the four ester active ingredients were those of bromoxynil octanoate and 2,4-D 2-ethylhexyl ester. Their vapour pressures were more than an order of magnitude lower than those of the preemergence-applied active ingredients. They were also lower than the vapour pressures of dicamba and clopyralid which were not desorbed, providing another example of the importance of polarity with respect to desorption. Approximately 5\% of bromoxynil octanoate and 2,4-D 2-ethylhexyl ester were desorbed from the clay soil. With a vapour pressure about an order of magnitude lower than those of bromoxynil octanoate and 2,4-D 2-ethylhexyl ester, approximately $2 \%$ of diclofop methyl ester was desorbed. Finally, fenoxaprop ethyl ester, whose vapour pressure was about two orders of magnitude lower, was less than $1 \%$ desorbed. The desorption experiments were carried out in September/October when average temperatures were 11.9 and $-3.9{ }^{\circ} \mathrm{C}$, respectively. Consequently, because of decreased vapour pressures, desorption of the active ingredients during highvolume sampling may have been somewhat lower than what may have occurred under warmer temperatures in late May to early July when herbicides are normally applied in the prairie region of Canada.

The relationship between vapour pressure and the proportion of active ingredient desorbed from the clay soil was investigated further by plotting the Log (percent desorbed) versus the Log (vapour pressure) (Figure 1). The plot shows a strong correlation between the percent desorbed and vapour pressure $\left(R^{2}=0.95\right)$ and that appreciable desorption occurs once vapour pressures exceed 1 $\mathrm{mPa}$. Thus, for non-polar active ingredients whose vapour pressures exceed $1 \mathrm{mPa}$, the proportion associated with the particulate fraction in the atmosphere, as determined by analysis of particulates captured on the glass fibre filter during high-volume air sampling, may be underestimated. This would result in a corresponding overestimation of the vapour component captured on the PUF/XAD-2 resin composite cartridge.

Only one soil type was investigated in the desorption experiments in the current study. The soil selected for fortification with active ingredients/hydrolysis products was a heavy clay soil (71\% clay, $29 \%$ silt and $10 \%$ sand) with low (3.1\%) organic matter content, typical of the area in which the desorption experiments were carried out. Adsorption/desorption studies, utilizing aqueous soil slurries, have shown that soil sorption coefficients for several herbicides were correlated with the organic matter content of soils [35,36] and wetland sediment [37]. However, vapours of low molecular weight organic compounds sorb mainly to the mineral component of dry low organic carbon content ( $2 \%)$ soils [38]. Thus, if soil with different organic matter and clay, silt and sand content had been used, then the extent of desorption of the various active ingredients (Table 3) may have been different.

There was significant variability (standard deviation) associated with the mean proportions of the various active ingredients and the hydrolysis product bromoxynil desorbed during high-volume air sampling (Table 3). Since temperature affects vapour pressure, one source of this variability could be variation in ambient air temperature which ranged from 1.6 to $21.6^{\circ} \mathrm{C}$ and -13 to $1.1{ }^{\circ} \mathrm{C}$ in September and October, respectively. Relative humidity also varied during the desorption experiments with daily minimum values varying from 17 to $89 \%$ and maximum values from 75 to $100 \%$. Chiou and Shoup [38] have shown that humidity affects adsorption of low molecular weight organic compounds to the greatest extent in low organic carbon content ( $2 \%)$ soils. In these soils, sorption of vapours of organic compounds is suppressed by water competition for active sites on the mineral component of 
the soil. Thus, diurnal and day-to-day changes during the 7-day sampling periods may have also contributed to the variability observed in the mean proportions of active ingredients/hydrolysis products desorbed. Finally, in each experiment, it was assumed that the average amount of any active ingredient detected in the ambient air (control) samples would have been collected on the PUF/XAD-2 resin composite cartridge of the samplers containing the fortified soil. Consequently, the desorbed amount in each experiment was "corrected" by subtracting the amount detected in the control sample. However, Bidleman [23] has pointed out that, during high-volume air sampling, vapours may be adsorbed by particles on the filter. In our experiments, vapours of the active ingredients may have sorbed to some extent on the relatively large amount of particulates ( $0.5 \mathrm{~g}$ soil) present on the filter. If so, "correcting" the desorbed amount by the amount detected in the control samples may have also contributed to the variability observed in the average proportion of each active ingredient desorbed.

Figure 1. Plot of percent active ingredient desorbed versus active ingredient vapour pressure using $\log _{10}$-transformed values. Values shown are for the three preemergence-applied (trifluralin, triallate, ethalfluralin) and four postemergence-applied (bromoxynil octanoate, diclofop methyl ester, 2,4-D 2-ethylhexyl ester, fenoxaprop ethyl ester) active ingredients.

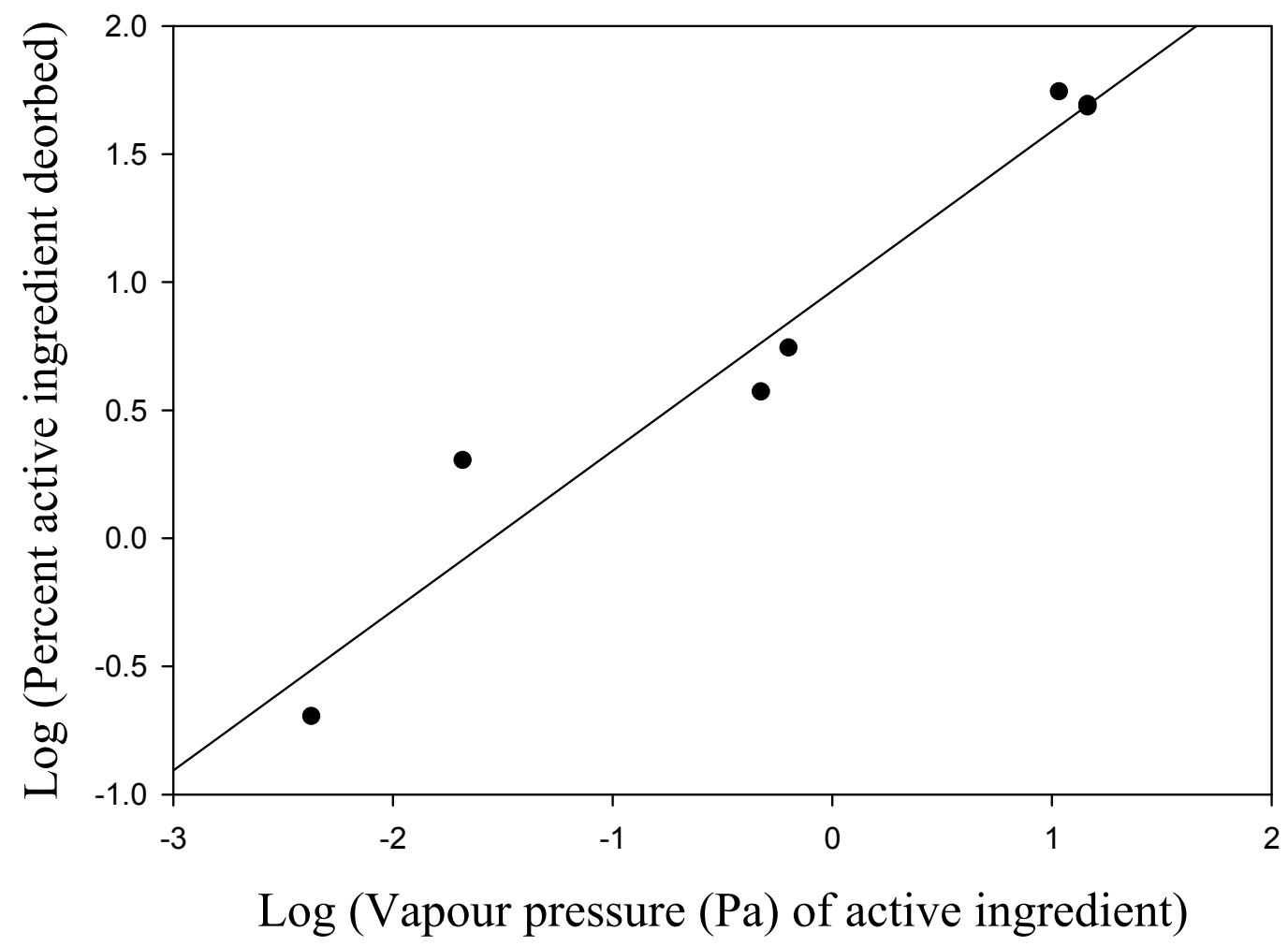

\section{Conclusions}

The phenomenon of pesticide stripping or desorption during high-volume air sampling was investigated by placing clay soil fortified with ten herbicide active ingredients commonly used in North America and seven hydrolysis products on the glass fibre filter preceding the PUF/XAD-2 resin composite cartridge in high-volume air samplers which were then operated for 7-day. The extent to which active ingredients/hydrolysis products were desorbed from the fortified soil was determined by 
analysis of the PUF/XAD-2 resin cartridges. Measurable amounts of the dimethylamine salts of 2,4-D, MCPA and dicamba and the six carboxylic acid hydrolysis products (2,4-D, MCPA, dicamba, mecoprop, diclofop, clopyralid) were not desorbed during high-volume air sampling. Approximately $0.1 \%$ of the less polar hydrolysis product bromoxynil was desorbed. Desorption of the post-applied ester active ingredients varied from 0.2 (fenoxaprop ethyl ester) to 5.5\% (bromoxynil octanoate) whereas approximately $50 \%$ of the preemergence-applied active ingredients (trifluralin, triallate, ethalfluralin) were desorbed. Desorption was linearly correlated with the vapour pressures of the active ingredients.

\section{References}

1. Majewski, M.S. Sources, Movement, and Fate of Airborne Residues. In Pesticide Chemistry: Advances in International Research, Development, and Legislation, Proceedings of the 7th International Congress of Pesticide Chemistry (IUPAC), Hamburg, Germany, 5-10 August 1990; Frehse, H., Ed.; VCH: Weinheim, Germany, 1991; pp. 307-317.

2. Bache, D.H.; Johnstone, D.R. Microclimate and Spray Dispersion, 1st ed.; Ellis Horwood Ltd.: London, UK, 1992.

3. Southcombe, E.S.E.; Miller, P.C.H.; Ganzelmeier, H.; van de Zande, J.C.; Miralles, A.; Hewitt, A.J. The International (BCPC) Spray Classification System Including a Drift Potential Factor. In Proceedings of the 1997 Brighton Crop Protection Conference-Weeds, Brighton, UK, November 1997; Volume 5, pp. 371-380.

4. Etheridge, R.E.; Womac, A.R.; Mueller, T.C. Characterization of the spray droplet spectra and patterns of four venturi-type drift reduction nozzles. Weed Technol. 1999, 13, 765-770.

5. White, A.W., Jr.; Harper, L.A.; Leonard, R.A.; Turnbull, J.W. Trifluralin volatilization losses from a soybean field. J. Environ. Qual. 1977, 6, 105-110.

6. Glotfelty, D.E.; Taylor, A.W.; Turner, B.C.; Zoller, W.H. Volatilization of surface-applied pesticides from fallow soil. J. Agric. Food Chem. 1984, 32, 638-643.

7. Grover, R.; Shewchuk, S.R.; Cessna, A.J.; Smith, A.E.; Hunter, J.H. Fate of 2,4-D iso-octyl ester after application to a wheat field. J. Environ. Qual. 1985, 14, 203-210.

8. Grover, R.; Smith, A.E.; Shewchuk, S.R.; Cessna, A.J.; Hunter, J.H. Fate of trifluralin and triallate applied as a mixture to a wheat field. J. Environ. Qual. 1988, 17, 543-550.

9. Grover, R.; Smith, A.E.; Cessna, A.J. Fate of bromoxynil $n$-butyrate and iso-octanoate applied as a mixture to a wheat field. J. Environ. Qual. 1994, 23, 1304-1311.

10. Smith, A.E.; Grover, R.; Cessna, A.J.; Shewchuk, S.R.; Hunter, J.H. Fate of diclofop-methyl after application to a wheat field. J. Environ. Qual. 1986, 15, 234-238.

11. Waite, D.T.; Cessna, A.J.; Grover, R.; Kerr, L.A.; Snihura, A.D. Environmental concentrations of agricultural herbicides: 2,4-D and triallate. J. Environ. Qual. 2002, 31, 129-144.

12. Larney, F.J.; Cessna, A.J.; Bullock, M.S. Herbicide transport on wind-eroded sediment. J. Environ. Qual. 1999, 28, 1412-1421.

13. Cessna, A.J.; Larney, F.J.; Kerr, L.A.; Bullock, M.S. Transport of the herbicide trifluralin on wind-eroded sediment. J. Environ. Qual. 2006, 86, 545-554. 
14. Smith, A.E.; Kerr, L.A.; Caldwell, B. Volatility of ethalfluralin, trifluralin, and triallate from a field following surface treatments with granular formulations. J. Agric. Food Chem. 1997, 45, 1473-1478.

15. Fryrear, D.W. Soil losses by wind erosion. Soil Sci. Soc. Am. J. 1995, 59, 668-672.

16. Glotfelty, D.E.; Leech, M.M.; Jersey, J.; Taylor, A.W. Volatilization and wind erosion of soil surface applied atrazine, simazine, alachlor, and toxaphene. J. Agric. Food Chem. 1989, 37, 546-551.

17. Shen, L.; Wania, F.; Lei, Y.D.; Teixeira, C.; Muir, D.C.G.; Bidleman, T.F. Atmospheric distribution and long-range transport behavior of organochlorine pesticides in North America. Environ. Sci. Technol. 2005, 39, 409-420.

18. Hill, B.D.; Harker, K.N.; Hasselback, P.; Inaba, D.J.; Byers, S.D.; Moyer, J.R. Herbicides in Alberta rainfall as affected by location, use and season. Water Qual. Res. J. Can. 2002, 37, 515-542.

19. Waite, D.T.; Cessna, A.J.; Gurprasad, N.P.; Banner, J. A new sampler for collecting separate dry and wet atmospheric depositions of trace organic chemicals. Atmos. Environ. 1999, 33, 1513-1523.

20. Waite, D.T.; Bailey, P.; Sproull, J.F.; Quiring, D.V.; Chau, D.F.; Bailey, J.; Cessna, A.J. Atmospheric concentrations and dry and wet deposits of some herbicides currently used on the Canadian prairies. Chemosphere 2005, 58, 693-703.

21. Ma, J.; Daggupaty, S.; Harner, T.; Li, Y. Impacts of lindane usage in the Canadian prairies on the Great Lakes ecosystem. 1. Coupled atmospheric transport model and modeled concentrations in air and soil. Environ. Sci. Technol. 2003, 37, 3774-3781.

22. Cessna, A.J.; Waite, D.T.; Kerr, L.A.; Grover, R. Duplicate sampling reproducibility of atmospheric residues of herbicides for paired pan and high-volume air samplers. Chemosphere 2000, 40, 795-802.

23. Bidleman, T.F. Atmospheric processes: Wet and dry deposition of organic compounds are controlled by their vapour-particle partitioning. Environ. Sci. Technol. 1988, 22, 361-367.

24. Majewski, M.S.; Capel, P.D. Pesticides in the Atmosphere: Distribution, Trends, and Governing Factors; Gilliom, R.J., Ed.; Ann Arbor Press, Inc.: Chelsea, MI, USA, 1995; Volume 1.

25. Smith, A.E. Comparison of solvent systems for the extraction of atrazine, benzoylprop, flamprop and trifluralin from weathered field soils. J. Agric. Food Chem. 1981, 29, 111-115.

26. Cessna, A.J.; Waite, D.T.; Constable, M. Concentrations of pentachlorophenol in atmospheric samples from three Canadian locations, 1994. Bull. Environ. Contam. Toxicol. 1997, 58, 651-658.

27. Grover, R.; Waite, D.T.; Cessna, A.J.; Nicholaichuk, W.; Ervine, D.G.; Kerr, L.A.; Best, B. Magnitude and persistence of herbicide residues in farm dugouts and ponds in the Canadian prairies. Environ. Toxicol. Chem. 1997, 16, 638-643.

28. Smith, A.E. Degradation of the herbicide diclofop-methyl in prairie soils. J. Agric. Food Chem. 1977, 27, 428-432.

29. Zepp, R.G.; Wolfe, N.L.; Gordon, J.A.; Baughman, G.L. Dynamics of 2,4-D esters in surface waters. Environ. Sci. Technol. 1975, 9, 1144-1151. 
30. Muir, D.C.G.; Kenny, D.F.; Grift, N.P.; Robinson, R.D.; Titman, R.D.; Murkin, H.R. Fate and acute toxicity of bromoxynil esters in an experimental prairie wetland. Environ. Toxicol. Chem. 1991, 10, 395-406.

31. The Pesticide Manual, 14th ed.; Tomlin, C.D.S., Ed.; British Crop Protection Council: Alton, UK, 2006.

32. Wauchope, R.D.; Buttler, T.M.; Hornsby, A.G.; Augustijn-Beckers, P.W.; Burt, J.P. The SCS/ARS/CES pesticide properties database for environmental decision-making. Rev. Environ. Contam. Toxicol. 1992, 123, 1-155.

33. Herbicide Handbook, 9th ed.; Senseman, S.A., Ed.; Weed Science Society of America: Lawrence, KS, USA, 2007.

34. Pankow, J.F. Gas/particle partitioning of neutral and ionizing compounds to single and multi-phase aerosol particles. 1. Unified modeling framework. Atmos. Environ. 2003, 37, 3323-3333.

35. Grover, R.; Banting, J.D.; Morse, P.M. Adsorption and bioactivity of di-allate, tri-allate and trifluralin. Weed Res. 1979, 19, 363-369.

36. Kozák, J.; Valla, M.; Prokopec, O.; Vacek, O. Prediction of the Role of Soil Organic Matter and some other Soil Characteristics in Herbicide Adsorption. In Humus, Its Structure and Role in Agriculture and Environment; Kubát, J., Ed.; Elsevier Science Publishers B.V.: Amsterdam, The Netherlands, 1992; Volume 25, pp.165-169.

37. Xu, D.; Meyer, S.; Gaultier, J.; Farenhorst, A.; Pennock, D. Land use and riparian effects on prairie wetland sediment properties and herbicide sorption coefficients. J. Environ. Qual. 2009, $38,1757-1765$.

38. Chiou, C.T.; Shoup, T.D. Soil sorption of organic vapors and effects of humidity on sorptive mechanism and capacity. Environ. Sci. Technol. 1985, 19, 1196-1200.

(C) 2011 by the authors; licensee MDPI, Basel, Switzerland. This article is an open access article distributed under the terms and conditions of the Creative Commons Attribution license (http://creativecommons.org/licenses/by/3.0/). 